\title{
RESPONSABILIDADE SOCIAL DAS EMPRESAS: CONSIDERAÇÕES SOBRE A HUMANIZAÇÃO DO CAPITAL
}

\author{
Jeferson Sousa Oliveira ${ }^{1}$ \\ Marcelo Benacchio ${ }^{2}$
}

\section{RESUMO}

Com o advento da globalização, muitas companhias emergiram no cenário econômico mundial, atuando de maneira a violar a dignidade humana, com isso passou-se a indagar o quão abrangente seria a sua responsabilidade social. O presente trabalho objetiva analisar a responsabilidade social das empresas sob um viés humanista, contribuindo para as discussões sobre o tema. Para tanto, utilizou-se o método hipotético-dedutivo e histórico, valendo-se ainda de revisão bibliográfica. Concluiu-se que o lucro não deve ser buscado como um fim em si, mas como um instrumento para a promoção do bem-estar social.

Palavras-chave: Globalização; Companhias Transnacionais; Direito Econômico; Humanização; Direitos Humanos.

\section{CORPORATE SOCIAL RESPONSIBILITY: CONSIDERATIONS ON THE HUMANIZATION OF CAPITAL}

\begin{abstract}
With the advent of globalization, many companies emerged in the world economic scenario, acting in a way that violated human dignity, with which they began to ask how comprehensive their social responsibility would be. This paper aims to analyze the social responsibility of companies under a humanist bias, contributing to the discussions on the theme. In order to do so, the hypothetical-deductive and historical method was used, as well as a bibliographic review. It was concluded that profit should not be sought as an end in itself, but as an instrument for the promotion of social welfare.
\end{abstract}

Keywords: Globalization; Transnational Companies; Economic Law; Humanization; Human Rights.

\section{INTRODUÇÃO}

Com o passar dos séculos, a atividade comercial ganhou força pelo mundo, ensejando o surgimento de modelos econômicos que prometiam levar a sociedade a um novo patamar, um no qual todos pudessem se beneficiar dos frutos das relações de mercado.

\footnotetext{
${ }^{1}$ Mestrando em Direito pela Universidade Nove de Julho (UNINOVE). Especialista em Direito Tributário pelo Complexo Educacional das Faculdades Metropolitanas Unidas (FMU). Pesquisador bolsista do Programa de Suporte à Pós-Graduação de Instituições de Ensino Particulares (PROSUP).

${ }^{2}$ Doutor e mestre em Direito pela Pontifícia Universidade Católica de São Paulo (PUC/SP). Professor permanente do Mestrado em Direito e da Graduação da Universidade Nove de Julho (UNINOVE). Professor Convidado da Pós Graduação lato sensu da PUC/COGEAE e da Escola Paulista da Magistratura.
} 
Ocorre que diversos problemas emergiram juntamente com a ampliação das relações comerciais no mundo, implicando na perpetração de discrepâncias econômicas entre aqueles que detinham a propriedade dos meios de produção e daquela que vendiam sua força de trabalho.

Frente ao advento da globalização, esses problemas ganharam maior extensão, afetando diferentes povos em países diversos, pois a atuação das companhias passara a violar direitos e garantias internacionalmente reconhecidas como inatas a todas as pessoas.

O abuso do poder econômico se tornou uma realidade, ensejando a insatisfação popular e o surgimento de inúmeros debates a respeito dos limites da responsabilidade das companhias por seus atos.

Assim, fundada nos Direitos Humanos, a responsabilidade social das companhias desponta como um dever social que visa retribuir a coletividade pelos danos causados em prol do exercício econômico, de modo a tentar melhorar o bem-estar coletivo, sem, contudo, desvirtuar a natureza empresarial das transnacionais.

Assemelhando-se a outros Estados, o Brasil também positivou em sua principal carta normativa, disposições que objetivam preservar o bem coletivo em face das predatórias relações de mercado, com o fito de guiar a economia nacional de modo mais humanista rumo à consecução de seus objetivos.

Deste modo, o presente trabalho possui caráter analítico, o qual se valerá do método hipotético-dedutivo e histórico, bem como de estudos bibliográficos a fim de abordar a problemática ora proposta.

\section{CAPITALISMO E GLOBALIZAÇÃO}

A prática de atos negociais sempre se fez presente na história humana, o que levou o comércio a ganhar força ao longo dos séculos.

Com todo esse crescimento, inevitavelmente a economia se tornaria alvo de diferentes analises, destacando-se dentre seus estudiosos, Adam Smith, considerado por muitos como o pai do capitalismo liberal.

Adam (2015), entendia que o cenário econômico ideal seria aquele onde inexistiria a intervenção do Estado, o que permitiria que o mercado se autorregulasse a partir da oferta e da 
procura, e que traria ainda benefícios à coletividade, vez que todos os indivíduos estariam sujeitos a ascender financeiramente.

Ocorre que este modelo se mostrou ineficiente para desenvolver a sociedade, vez que concentrou a renda e criou discrepâncias econômicas significativamente danosas à coletividade.

Como resposta ao severo desequilíbrio econômico disseminado pelo capitalismo liberal, por volta do século XVIII, surgiram os primeiros teóricos da doutrina socialista, ganhando destaque Henri de Saint Simon.

Contrapondo-se ao capitalismo - que defendia o individualismo e a propriedade privada dos meios de produção - o modelo socialista buscava proteger a classe proletária, principalmente pela correta distribuição do produto do trabalho humano e pelo dirigismo dos interesses econômicos do Estado.

Inicialmente, a intervenção do Estado aparentou ser uma saída para os problemas advindos do liberalismo econômico, pois "mesmo ainda ao tempo do liberalismo o Estado era, seguidas vezes, sempre no interesse do capital, chamado a 'intervir' na economia." (GRAU, 2015, p.21)

Com o surgimento das teorias de Karl Marx e Friedrich Engels, o socialismo ganhou força, trazendo a publicização dos meios de produção e a economia planificada como instrumentos do Estado ideal.

No embate entre a proteção dos interesses individuais e coletivos, o capitalismo liberal viu-se obrigado a adotar um viés que melhor atendesse aos interesses da população, a fim de não perder espaço para a emergente corrente socialista.

Com isso surge em meados do século XIX, o Estado de Bem-Estar Social. Nesse modelo buscou-se amparar a coletividade sem que isso implicasse na intervenção estatal na economia, mas sim como agente protetor do bem-estar do povo.

A implementação de diversas garantias sociais acabou por onerar os cofres públicos, o que acarretou o aumento dos impostos, penalizando aqueles que deveriam usufruir da proteção conferida pelo Estado.

John Maynard Keynes, no inicio da década de 1920, emergiu com o que se convencionou chamar de neoliberalismo econômico. Esse modelo busca mitigar as discrepâncias perpetradas pelo liberalismo, assim como reduzir os elevados custos típicos do Estado do Bem-Estar Social. 
O neoliberalismo defende ainda um posicionamento intervencionista do Poder Público, a fim de guiar a economia estatal conforme seus interesses, sem que isso interfira na livre iniciativa e na livre concorrência, salvo para preservar o equilíbrio do mercado.

Com isso, o modelo idealizado por Keynes se tornou o mais adotado no mundo moderno, o que não impediu que diversas violações aos direitos e garantias fundamentais ocorressem nas últimas décadas.

A intervenção estatal em maior ou menor grau se mostrou importante para o equilíbrio do mercado, pois o ser humano foi alvo de inúmeros abusos e privações ao longo da história, tudo em prol do desenvolvimento puramente econômico.

A busca pelo lucro implicou no surgimento de um modelo de atuação empresarial pautado no lucro como um fim em si, o que para alcançar esse objetivo, fez as companhias não medirem esforços.

Com o surgimento da internet e a popularização dos computadores, o mundo passou a vivenciar uma nova realidade, uma na qual pessoas, empresas e governos passaram a estar diretamente interligadas, podendo ainda, transmitir informações em tempo real para qualquer parte do planeta. Para muitos, esse foi o marco inicial do que se tem atualmente como globalização.

Embora a globalização não tenha um marco inicial precisamente definido, é certo que as relações sociais, financeiras, econômicas e políticas ganharam um novo contexto, dotado de maior amplitude, o que ensejou reflexos positivos e negativos em todo o mundo.

No entanto, esse estado de integração não é novo, haja vista possuir suas raízes em diferentes fatores históricos, os quais guiaram a tecnologia e o comércio para o que se conhece atualmente.

Há cerca de 150 anos, a diminuição dos custos das comunicações e dos transportes deu origem ao fenômeno que pode ser considerado precursor da globalização. Até então, a maior parte do comércio era local; foram as mudanças do século XIX que levaram à formação das economias nacionais e ajudaram a fortalecer o Estado-Nação. Os governos foram pressionados por novas demandas: os mercados podiam estar produzindo crescimento, mas eram acompanhados por novos problemas sociais e, em alguns casos, até econômicos. (STIGLITZ, 2007, p. 83) 
Como fruto do processo de globalização, surgiram as companhias transnacionais, emergindo como reflexo da adaptabilidade da empresa as novas tendências do mercado moderno.

Ante a celeridade intrínseca às relações negociais, as empresas transnacionais perceberam que poderiam se valer da mobilidade de suas filiais e agencias para melhor desfrutar do que os diversos Estados tinham a lhes oferecer. Conforme destaca Bauman, (1999, p. 15), “a mobilidade tornou-se o fator de estratificação mais poderoso e mais cobiçado, a matéria de que são feitas e refeitas diariamente as novas hierarquias sociais, políticas, econômicas e culturais em escala cada vez mais mundial."

Ocorre que a alocação dessas companhias em diferentes países normalmente é precedida por uma série de negociações, das quais resultam benefícios e problemas a serem suportados pelo Estado e pela sociedade.

Isso decorre do fato de que as companhias transnacionais, em muitos casos, optam por se alocar em países não desenvolvidos, cujo sistema normativo é falho, o que as permite atuar com maior liberdade, violando uma série de direitos e garantias inatas aos seres humanos, em prol do desenvolvimento puramente econômico.

La empresa es, sin duda, una de las instituciones sociales más importantes y con un mayor poder de influir, positiva o no tan positivamente, en el sistema económico, natural y social. En este sentido, no cabe duda de que sobre la empresa recae parte de la responsabilidad de la situación actual de dicho sistema. Pero no podemos colegir de elle que los impactos negativos de la empresa hayan sido conscientes. No podemos culpabilizar a la empresa como instituición. Lo que hemos de pensar es que la concepción tradicional de la empresa es hija de su tiempo, es decir, del paradigma cultural predominante. (SANTONJA, 2009, p. 35-36)

Descabido é culpabilizar as companhias por todas as mazelas sociais, mas é inegável que elas possuem uma parcela da responsabilidade pelos danos que provocarem em decorrência do exercício de sua atividade, ainda que indiretamente.

Parte da responsabilidade pelas violações às garantias individuais, coletivas e sociais ocorridas nos Estados menos desenvolvidos se dá em virtude da deficiência do sistema normativo ou por consequência de outros fatores, como a má gestão pública, a corrupção ou pela pressão exercida pelas companhias atuantes em determinados segmentos. 
Com isso, muitos Estados se veem compelidos a tolerar a atuação das companhias, mesmo que isso implique na destruição do meio ambiente e na exploração da mão de obra em condições subumanas, com jornadas laborais exaustivas.

Os efeitos negativos da atuação as companhias transnacionais são ainda mais fortes em países carentes de postos laborais, pois a saída migração dessas companhias é capaz de gerar uma onda de desemprego e o agravamento das já fragilizadas políticas públicas, ascendendo a insatisfação popular. Conforme versa Bauman (1999, p. 15) "a companhia é livre para se mudar, mas as conseqüências da mudança estão fadadas a permanecer."

Dentre os efeitos que costumeiramente permanecem, estão, como aduzido, o desemprego, assim como os danos ambientais e a queda na arrecadação fiscal do Estado, o que reflete no financiamento das políticas públicas.

Michael M. Weinstein (2005), aponta que ao se depararem com ausência de oportunidades laborais, inúmeras pessoas optam por migrar para outra região ou para outro país, ainda que ilegalmente. Por outro lado, o Estado, mesmo reprimindo esse tipo de ingresso em seu território, não pode negar o reflexo econômico que terá com a queda do consumo de bens nacionais por parte dessas pessoas.

Deste modo, milhares de pessoas ao redor do mundo deparam-se com uma gama de privações que lhes impedem de desfrutar da dignidade em toda a sua plenitude em decorrência da desigualdade de condições com aquelas que vivem em países mais ricos.

Por outro lado, viver em países desenvolvidos não é uma garantia de possuir melhor qualidade de vida e justa distribuição de renda, pois nesses também há pessoas que vivem à margem do bem-estar.

Nos países mais ricos é demasiado comum haver pessoas imensamente desfavorecidas, carentes das oportunidades básicas de acesso a serviços de saúde, educação funcional, emprego remunerado ou segurança econômica e social. Mesmo em países muito ricos, às vezes a longevidade de grupos substanciais não é mais elevada do que em muitas economias mais pobres do chamado Terceiro Mundo. (SEN, 2010, p. 29)

Destarte, ante todas as implicações apontadas, começou-se a questionar a amplitude da responsabilidade social - ou responsabilidade corporativa - das empresas transnacionais, tema este que ganhado espaço dentre os debates modernos.

\section{A RESPONSABILIDADE SOCIAL DAS COMPANHIAS TRANSNACIONAIS}


Como aduzido, muitas companhias, ao buscarem se alocar em um Estado, acabam por negociar com seus governos condições mais benéficas para a sua instalação, conquistando isenções, subsídios e outros benefícios de ordem diversa.

Com isso, a atuação das companhias é responsável por causar uma série de danos à sociedade na qual ela está inserida, violando diversos direitos e garantias individuais, coletivas e sociais.

Os maiores impactos normalmente atingem a ceara ambiental e laboral, devido à necessidade de extração de recursos naturais e a exposição de trabalhadores a condições exaustivas ou subumanas de trabalho.

A ânsia de crescer financeiramente e ganhar espaço no concorrido mercado internacional, fez com que muitas empresas tivessem o lucro como um fim em si mesmo, não se preocupando com o ambiente ao seu entorno, haja vista a adoção de um modelo clássico de responsabilidade social adstrito apenas a gerar empregos e pagar tributos.

Segundo Bauman (1999) a negativa das companhias em arcar com o custeio de atividades sociais se dá em virtude de não se sentirem responsáveis pelos indivíduos alheios à sua atividade.

Infelizmente muitas companhias ainda detêm essa política, no entanto, isso tende a mudar ao longo dos anos, pois com a interligação dos meios de comunicação, noticias circulam com relativa imediatividade, o que torna internacional a visibilidade das condutas das companhias, principalmente quanto a sua forma de tratamento aos clientes e a preservação do meio ambiente.

Essa situação é notória quando se trata de companhias com ativos negociados no mercado de capitais, os quais acabam por sofrer severas oscilações quando a imagem da empresa se vincula a condutas tidas como negativas, implicando na perda de milhões de dólares em um curto lapso temporal.

Com isso, surgiram indagações ao redor do mundo quanto à extensão da responsabilidade das companhias, o que refletiu em no surgimento de uma nova correte, mais ampla e que vai muito além do mero pagamento de tributos e criação de postos laborais.

El modelo capitalista y la Responsabilidad Social de la Empresa (RSE), también llamada Responsabilidad Corporativa (RC), está en el centro del debate económico, social y político en todo el mundo desarrollado. Existen grandes controversias sobre su alcance en el ámbito de lá empresa y se 
plantea la pergunta de si estamos ante una auténtica, potente y novedosa herramienta de gestión empresarial que comporta una nueva economía de la empresa y, como consecuencia de ello, se abre paso una reformulación del modelo capitalista liberal. (SANTONJA, 2009, p. 27)

O novo modelo de responsabilidade social está atrelado a uma nova forma de gestão das companhias, mais preocupada com as pessoas que a orbitam, os chamados stakeholders. Assim, a responsabilidade social passou a abarcar também a proteção ao consumidor, ao meio ambiente, à educação e a outros aspectos que compõem a dignidade humana sob todas as suas formas.

Nesse sentido, a função social da empresa não consiste - apenas - em manter a atividade empresarial como geradora de empregos, tributos e riquezas. Defende-se uma compreensão mais ampla da função social da empresa, no contexto do Estado Democrático de Direito. (PEREIRA e MAGALHÃES, 2016, p. 57)

A conscientização dos acionistas e gestores das companhias quanto ao papel destas na sociedade é o primeiro passo para a mudança espontânea da cultura empresarial, pois temse que apenas o cumprimento da responsabilidade social imposta pela lei não passará de mera formalidade para o desempenho da atividade econômica em solo estrangeiro, não correspondendo a um valor comum e inato ao ser humano, incapaz, deste modo, de ser observado em todos os países em que as transnacionais se façam presentes.

No mais, muitas companhias adotam essa nova modalidade de responsabilidade social como uma forma de marketing, pois já perceberam a importância da opinião pública e como isso é capaz de influenciar nos resultados financeiros da empresa.

As empresas na sociedade contemporânea que não se ajustarem a programas de responsabilidade social estruturados estão fadadas ao insucesso, porque a responsabilidade social é fator competitivo e somente vão sobreviver aquelas que tiverem o espírito cidadão, visando não só a obtenção de lucro, mas também preocupadas em garantir a qualidade de vida dos indivíduos e da sociedade como um todo. (CUNHA e DOMINGOS, 2011, p. 152).

Não se pode olvidar que a atuação danosa das companhias não prejudica apenas àqueles alheios a sua atividade, mas também aos próprios integrantes da companhia, pois os impactos negativos das condutas empresariais vão além do local no qual ocorreram, possuindo reflexos para além das fronteiras geopolíticas. 
Deste modo, torna-se lógico exigir que as companhias dispendam parte do seu esforço na busca por meios capazes de contribuir com o bem-estar social, seja por ações positivas ou pela simples abstenção de causar maiores danos à coletividade.

Cabe esclarecer que não se busca transmudar as transnacionais em entidades beneficentes - haja vista sua natureza empresarial e sua finalidade precípua, obter lucro - mas apenas conscientizar seus dirigentes quanto à necessidade de estabelecer melhores condições para aqueles que dela dependam direta ou indiretamente.

Sob essa óptica, José Renato Nalini (2011, p. 128), entende que "não se imagina que a empresa só pense no próximo. Ela é uma organização que visa o lucro. Não é entidade filantrópica. Mas pode pensar também no próximo."

Assim, mais do que um interesse econômico, a responsabilidade social das companhias deve ser tida como um dever social, pois não é justo que as empresas explorem, enquanto lhes for conveniente, todo o meio que as cercam e concentrem os frutos dessa exploração, sem que disso decorram maiores benefícios à coletividade.

\section{CONSTITUIÇÃO BRASILEIRA E A HUMANIZAÇÃO DO CAPITAL}

A tão desejada conscientização dos dirigentes das transnacionais quanto à responsabilidade social destas está atrelado a um fator comum a diferentes povos, os direitos humanos.

Embora existam direitos que sejam próprios de cada povo, constituídos com base em sua cultura e história, internacionalmente, a maioria dos Estados modernos têm reconhecido os Direitos Humanos como inatos a todos os povos, razão essa que contribuiu para o seu rápido desenvolvimento perante a comunidade internacional.

Em suma, os Direitos Humanos são fruto da evolução histórica da humanidade. Sua concepção atual foi moldada a partir de aspectos religiosos, filosóficos e científicos que ocorreram ao decorrer dos séculos (COMPARATO, 2010), possuindo como marco recente, a Declaração da Virginia, de 1776, e a Declaração dos Direitos do Homem e do Cidadão, de 1789.

Destaca-se que não se ignora outros diplomas que precedem as referidas declarações, no entanto, estas merecem destaque por consubstanciar direitos que mais tarde a doutrina viria a classificar como de primeira dimensão ou geração. 
Ambas as declarações trouxeram em seu bojo direitos de significativa importância, tidos como precursores de muitas outras garantias, notadamente o direito de insurgência contra o Estado - Declaração da Virginia - e a os direitos civis e políticos - Declaração dos Direitos do Homem e do Cidadão.

Entretanto, o surgimento dessas garantias não foi capaz de proteger os cidadãos da exploração e do abuso, pois com a perda de poder do Estado, aqueles que detinham os meios de produção passaram a ditar as regras da sociedade, afinal, eram escassas as oportunidades de labor.

Como descrito, as péssimas condições laborais oferecidas aos empregados fez com que esses buscassem a intervenção do Estado na tentativa de garantir-lhes o respeito a sua dignidade. Foi então que surgiu o Estado do Bem-Estar Social, assim como os Direitos Humanos de segunda dimensão ou geração - direitos sociais, econômicos e culturais.

Após o final da Segunda Guerra Mundial, a partir de violações nela ocorridas, a luta pela defesa dos Direitos Humanos ganhou um difuso, com direitos que vão além do cidadão ou de determinado povo, mas que compreendem a todos sem qualquer distinção.

Os direitos de terceira dimensão surgem no contexto do Estado democrático e social de direito, ultrapassando a visão individualista, superando a dicotomia existente entre o público e o privado, fazendo com que a tutela dos direitos atinja um caráter difuso. (MATOS e FEDERIGHI, 2016. p. 102.)

Deste modo, ante essa construção histórica de valores inatos, permitir que as companhias transnacionais ajam de modo a desrespeitar garantias internacionalmente estabelecidas é um retrocesso na defesa da dignidade humana, razão esta que fez muitos Estados positivarem princípios e normas a fim de guiar a atividade econômica exercida em seu território rumo à consecução de seus interesses.

O Brasil não fez diferente e trouxe em sua Carta Magma diversos dispositivos que visam propiciar ao seu povo o respeito à dignidade humana e o direito a uma existência digna, sem que disso decorra a inviabilização do mercado interno.

Mais do que um direito, a dignidade humana é tida como um dos fundamentos da República Federativa do Brasil - previsto no artigo $1^{\circ}$, III da $\mathrm{CF}$ - e que visa auxiliar na conquista dos objetivos nacional, tal como a promoção do bem de todos (art. $3^{\circ}, \mathrm{IV}, \mathrm{CF}$ ) 
Não se pode olvidar ainda que o principio da dignidade atua em conjunto com os valores sociais do trabalho e da livre iniciativa, ambos presentes artigo $1^{\circ}$ inciso IV da CF, demonstrando o caráter social do ordenamento pátrio, sem se dissociar do modelo capitalista de economia.

Continuando, o artigo 170, I traz a soberania nacional como um dos princípios que conduzem a ordem econômica no Brasil. Este princípio é dotado de significativa importância, notadamente por visar cessar com a dependência econômica a Estados estrangeiros e organismos internacionais, possibilitando às empresas brasileiras maior competitividade no mercado externo.

Cabe destacar que a soberania nacional presente no artigo 170, I da Carta Magna, possui natureza econômica, diversamente daquela prevista no $1^{\circ}$, I, do mesmo diploma normativo, haja vista esta deter natureza política e objetivar combater a ingerência de Estados estrangeiros na tomada de decisões do governo nacional. (GRAU, 2015)

O artigo 170, II prevê a propriedade privada como um dos diferentes princípios da ordem econômica brasileira, a qual encontra sua limitação na função social, expressamente prevista no inciso seguinte, também como princípio econômico, visando coibir o abuso do poder econômico e impor limites ao exercício da autonomia privada.

Importante esclarecer que a propriedade e a função social previstas no artigo 170, II e III, constituem diretrizes da ordem econômica, versando sobre a titularidade dos meios de produção, os quais estão diretamente ligados à livre iniciativa (art. 170, caput) e a livre concorrência (art. 170, IV), razão pela qual não devem ser confundidos com aqueles elencados no artigo $5^{\circ}$, XXII e XXIII, também da Constituição Federal. Estes, por seu turno, consubstanciam-se em direitos e garantias de natureza individual e coletiva, tratando sobre a propriedade geral.

A livre iniciativa (art. 170, IV) é um dos elementos que denotam a postura ideológica do Brasil, voltada ao incentivo da participação de novos empreendimentos no mercado, o que acaba por beneficiar a coletividade através do acesso a diferentes ofertas de produtos e serviços, bem como, maior variação de preços.

A defesa do consumidor (art. 170, V) é de grande importância para o correto funcionamento do mercado, pois os consumidores são o destino de toda a produção de bens e prestação de serviços, ou seja, são a força motriz do capitalismo, sem o qual inexistem motivos para se atuar no cenário econômico. 
A proteção ao consumidor deve ocorrer de forma ampla, tanto de maneira preventiva quanto repressiva, de modo que estes não estejam submetidos abusivamente aos interesses das companhias.

Impossível é tratar sobre produção e consumo e não abordar a defesa ao meio ambiente. Está encontra-se precisar no inciso VI do artigo 170 da Constituição Federal, e é reflexo da luta internacional pela preservação do meio ambiente, o qual está sendo severamente degradado em prol do desenvolvimento puramente econômico.

Ao mesmo tempo em que se impõe o aumento da produção de bens negociáveis, o meio ambiente adentra mais em uma situação delicada, pois não consegue se recuperar a tempo de suprir a demanda por recursos naturais.

O artigo 170, no inciso VII, traz a redução das desigualdades regionais e sociais como um princípio, no entanto, este também se encontra tipificado no artigo $3^{\circ}$, III da $\mathrm{CF}$, como um dos objetivos da República Federativa do Brasil.

Para que se possa conquistar esse objetivo, devem ser empregadas formas eficazes de combate à pobreza, principalmente no que toca à correta distribuição de renda, vez que sua concentração cria as tão indesejadas discrepâncias econômicas combatidas há décadas.

Dir-se-á que a Constituição, aí, nada mais postula, no seu caráter de Constituição dirigente, senão rompimento do processo de subdesenvolvimento no qual estamos imersos e, em cujo bojo, pobreza, marginalização e desigualdades, sociais e regionais, atuam em regime de causação circular acumulativa - são causas e efeitos de si próprias. (GRAU, 2015, p. 215)

O princípio da busca pelo pleno emprego (art. 170, VIII) tem como objetivo incentivar a criação de novos postos de trabalho, permitindo com isso, que o maior número de pessoas possível possa laborar.

Esse princípio se coaduna com o artigo $6^{\circ}$ da Constituição Federal ao prever o trabalho como um direito social, assim como ao artigo $7^{\circ}$, XXVII, por entender que a evolução da tecnologia por meio da automação é uma ameaça ao pleno emprego.

Ao considerar o tratamento favorecido para as empresas de pequeno porte constituídas sob as leis brasileiras e que tenham sua sede e administração no país (art. 170, IX), buscou-se incentivar também a livre iniciativa, a fim de auxiliar na conquista da soberania econômica do país. 
Essa inter-relação entre princípios e objetivos constitucionais, segundo André Ramos Tavares (2011) não deve se abster apenas a ceara normativa, sendo importante considerar também a integração sob uma óptica moral, política e cultural.

Como se pôde verificar, todos esses princípios elencados constitucionalmente surgem para proteger os cidadãos de eventuais violações a sua dignidade, visando coibir que o lucro seja buscado como um fim em si, criando a figura do homo economicus, ou seja, aquele que visa o lucro acima de tudo.

Desta forma, o Brasil, pautado em valores internacionalmente reconhecidos e adequados à realidade nacional, intentou estabelecer em seu principal diploma normativo um modelo ideal de atuação empresarial no cenário econômico nacional, pautado no respeito à dignidade humana.

Há ainda diversos outros dispositivos constitucionais que visam reger a atividade econômica no Brasil, no entanto, abordar todos demandaria uma analise mais aprofundada do tema, o que não seria comportado pela natureza do presente estudo.

Entretanto, como aduzido, frente a todos os danos causados em prol do desenvolvimento puramente econômico, as companhias não devem ser abster em adotar um posicionamento mais responsável e preocupado com os stakeholders, pois o mero cumprimento da responsabilidade legalmente imposta não é suficiente para atender aos anseios sociais.

Esta realidad da lugar a un modelo capitalista menos economicista, más humanista y solidário y al mismo tiempo más rentable, que afirma una economía de mercano sana y eficiente en el marco de la globalización, basada en la RSE como nueva y eficaz herramienta de gestión empresarial. (SANTONJA, 2009, p. 28)

Destarte, as relações econômicas exercidas no mundo, principalmente em solo nacional, devem adotar um viés mais humanista, preocupado com o bem-estar da população e do meio no qual estão insertos, de modo a combater qualquer privação que possa ocasionar violações a sua dignidade.

\section{CONCLUSÃO}


Com o desenvolvimento da economia ao longo dos séculos, a atividade comercial ganhou posição de destaque no cenário internacional, trazendo a ideia de que por intermédio dela toda a coletividade poderia se beneficiar financeiramente.

Diversos problemas advieram desse entendimento, notadamente em decorrência do abuso do poder econômico por parte daqueles que detinham os meios de produção.

A evolução dos meios de comunicação foi determinante para novas mudanças nos valores sociais, financeiros, econômicos e políticos no mundo, iniciando a era da globalização, o que requereu das empresas maior adaptabilidade, emergindo assim, o que se viria a denominar de companhias transnacionais.

Tais companhias se difundiram em diferentes Estados na busca por melhores condições para a exploração de sua atividade, utilizando todo o seu poder econômico para negociar benesses, que em muitos casos, são direta e indiretamente prejudiciais à própria comunidade na qual optam por se instalar.

Muito embora as companhias não sejam as únicas responsáveis pelas diversas violações a Direitos Humanos no desempenho de sua atividade, essas ainda assim possuem uma parcela de culpa, razão pela qual deve ser responsabilizadas por seus atos.

Nascem com isso, novas indagações quanto à responsabilidade social das companhias, haja vista o modelo clássico não se mostrar suficiente para atender os anseios sociais.

A responsabilidade das companhias surge como uma forma de combater a busca pelo lucro a qualquer preço, demandando dos agentes exploradores da atividade econômica maior preocupação com o meio no qual estão insertas.

Por visar impedir que tantos direitos inatos aos seres humanos sejam violados em diferentes Estados, a adoção de um posicionamento empresarial mais humanista deve ter por base os Direitos Humanos, internacionalmente consagrados.

Para que se tenha essa cultura empresarial, faz-se necessário a conscientização daqueles que determinam os rumos das companhias, de forma estabelecer a responsabilidade como um valor inato a sua atividade, sendo observado em todos os países onde atuem.

Muitos Estados, visando defender o bem-estar de seus habitantes, optaram por positivar os Direitos Humanos levando em consideração aspectos internos para que aqueles melhor se adaptem a sua realidade. 
Nessa linha, o Brasil estabeleceu a dignidade humana como um de seus fundamentos, ao lado dos valores sociais do trabalho e da livre iniciativa. Visando auxiliar a República na consecução de seus objetivos, notadamente a promoção do bem de todos.

Com isso, buscou-se dar ao exercício da atividade econômica desenvolvida no país um caráter mais humanista, sem que o lucro seja um fim em si, mas apenas um instrumento para a promoção do bem coletivo.

Conclui-se assim, que a humanização da atividade econômica reflete uma necessidade moderna, pois a obtenção de lucro sem a promoção do bem-estar social não se justifica, principalmente quando exige o sacrifício de elementos que compõem a dignidade humana.

\section{REFERÊNCIAS}

BAUMAN, Zygmunt. Globalização: consequências humanas. Tradução: Marcus Penchel. Rio de Janeiro: Zahar, 1999.

BRASIL. Constituição Federal de 1988. Brasília: Congresso Nacional, 1988.

BRITTO, Carlos Ayres. O humanismo como categoria constitucional. 1. ed. 3. reimp. Belo Horizonte: Fórum, 2016.

COMPARATO, Fábio Konder. A afirmação histórica dos direitos humanos. 7. ed. ver. e atual. São Paulo: Saraiva. 2010.

CUNHA, Leandro Reinaldo da; DOMINGOS, Terezinha de Oliveira. A responsabilidade da empresa como garantia do desenvolvimento econômico e social. In: SILVEIRA, Vladmir Oliveira da; MEZZAROBA, Orides. (coord.). Empresa, sustentabilidade e funcionalização do direito. v. 2. São Paulo: Editora Revista dos Tribunais, 2011.

GRAU, Eros Roberto. A ordem econômica na Constituição de 1988. 17 edição. São Paulo: Malheiros, 2015.

LEOPOLDINO DA FONSECA, João Bosco. Direito Econômico. 8. ed. rev. e atual. Rio de Janeiro: Forense, 2015. 
MATOS, Leonardo Raphael Carvalho de; FEDERIGHI, Suzana Maria Pimenta Catta Preta. As teorias comparadas da função social da empresa. In: BENACCHIO, Marcelo (Coord.). A sustentabilidade da relação entre empresas transnacionais e direitos humanos. Curitiba: CRV, 2016. p. 102.

NALINI, José Renato. Sustentabilidade e ética empresarial. In: SILVEIRA, Vladmir Oliveira da; MEZZAROBA, Orides. (coord.). Empresa, sustentabilidade e funcionalização do direito. v. 2. São Paulo: Editora Revista dos Tribunais, 2011.

PEREIRA, Henrique Viana; MAGALHÃES, Rodrigo Almeida. A função social das sociedades transnacionais. In: BENACCHIO, Marcelo (Coord.). A sustentabilidade da relação entre empresas transnacionais e direitos humanos. Curitiba: CRV, 2016.

SANTONJA, Aldo Olcese. El Capitalismo Humanista. Madrid: Marcial Pons, 2009.

SEN, Amartya. Desenvolvimento como liberdade. Tradução Laura Teixeira Motta. São Paulo: Companhia das Letras, 2010.

SMITH. Adam. A riqueza das nações. $3^{\text {a }}$ ed. reimpr. Curitiba: Juruá, 2015.

STIGLITZ. Joseph E. Globalização: como dar certo. Trad. Pedro maia Soares. São Paulo: Companhia das Letras, 2007.

TAVARES, André Ramos. Direito constitucional econômico. 3. ed. São Paulo: Método, 2011.

WEINSTEIN, Michael M. Globalization: what's new?. New York: Columbia University Press, 2005. 